\title{
Corrigendum: The zinc-finger domains of PARP1 cooperate to recognize DNA strand breaks
}

Ammar A E Ali, Gyula Timinszky, Raquel Arribas-Bosacoma, Marek Kozlowski, Paul O Hassa, Markus Hassler, Andreas G Ladurner, Laurence H Pearl \& Antony W Oliver

Nat. Struct. Mol. Biol. 19, 685-692 (2012); published online 10 June 2012; corrected after print 10 July 2015

In the version of this article initially published, the image in the bottom row of Figure 4a (full-length PARP1-EGFP mutant R138E) was mistakenly replaced with a duplicate of the bottom-row image in Figure 4c (full-length PARP1-EGFP mutant M43D F44D) during preparation of the accepted version of the manuscript, after peer review and editorial evaluation had taken place. The error has been corrected in the HTML and PDF versions of the article. 